\title{
PENGARUH MODUL BERGAMBAR TERHADAP PENINGKATAN KEBERHASILAN TOILET TRAINING ANAK TODDLER DI PUSKESMAS SIBELA SURAKARTA
}

\author{
Ros Endah Happy Patriyani, Sunarsih Rahayu \\ Kementerian Kesehatan Politeknik Kesehatan Surakarta Jurusan Keperawatan
}

\begin{abstract}
Pictured module, Toilet Training, Toddler. One of development stage that must achieve in $1-3$ years old (toddler) is toilet training. In toddler, ability of sfingter uretra that was functioned for controlled sensation want to defecation and sensation want to urinary started developmented so that its sfingter more ability for controlling sensation want to urinary and sensation want to defecation. Each child had deference of ability and time in reach its ability. One of strategi that can was used to parent for help ready to toilet training for child with used pictured module. Knowing is effect of pictured module conduct to increased of resulting toilet training of toddler in work of area of sibela primary health care of Surakarta. The study was using quasi eksperiment methode with pre test - post test design. Analize data was using dependent $t$ test. Pictured module can increased of resulting toilet training of toddler with value of $p=0.002$. Occurs increased of resuting toilet training 1.070 point, with correlation level is low (correlation value was 0.683). Nurse must give support for mothers of toddler, and usually monitored increased of resulting of toilet training for toddler periodically in work of area of Sibela Primary Health Care of Surakarta.
\end{abstract}

Key Words : Pictured module, Toilet Training, Toddler.

Abstrak : Modul Bergambar, Toilet Training, Toddler. Salah satu tahap perkembangan yang harus dicapai pada anak usia $1-3$ tahun (toddler) adalah toilet training. Pada toddler, kemampuan sfingter uretra yang berfungsi untuk mengontrol rasa ingin defekasi dan rasa ingin berkemih mulai berkembang sehingga sfingter tersebut semakin mampu mengontrol rasa ingin berkemih dan rasa ingin defekasi. Namun demikian, setiap anak mempunyai kemampuan dan waktu yang berbeda dalam pencapaian kemampuan tersebut. Salah satu strategi yang dapat digunakan orangtua untuk membantu mempersiapkan anak toilet training dengan menggunakan modul bergambar. Penelitian ini dilakukan untuk mengetahui pengaruh modul bergambar terhadap peningkatan keberhasilan toilet training anak toddler di wilayah kerja Puskesmas Sibela Surakarta. Penelitian ini adalah penelitian quasi eksperimen dengan desain pre test-post test. Populasi penelitian ini anak toddler di wilayah kerja Puskesmas Sibela Surakarta. Sampel yang diambil dengan cara purposive sampling. Analisa data menggunakan uji $\mathrm{t}$ dependen. Hasil penelitian menunjukkan modul bergambar dapat meningkatkan keberhasilan toilet training pada anak toddler dengan nilai $\mathrm{p}=0.002$. Terjadi peningkatan keberhasilan toilet training 1.070 point, dengan tingkat korelasi rendah yaitu nilai korelasi 0.683 . Perawat dan kader posyandu hendaknya memberikan dukungan pada ibu-ibu toddler di Posyandu Balita 
Sejahtera Tegal Mulyo RT 3 RW 4 Mojosongo Surakarta, agar termotivasi dalam meningkatkan keberhasilan toilet training yang optimal.

\section{Kata Kunci : Modul Bergambar, Toilet Training, Toddler.}

Salah satu tahap perkembangan yang harus dicapai pada anak usia $1-3$ tahun (toddler) adalah toilet training (Hockenbery, Wilson, \& Wong, 2012). Toilet training adalah melatih anak buang air kecil (BAK) dan buang air besar (BAB) pada tempatnya. Pada toddler, kemampuan sfingter uretra yang berfungsi untuk mengontrol rasa ingin defekasi dan rasa ingin berkemih mulai berkembang sehingga sfingter tersebut semakin mampu mengontrol rasa ingin berkemih dan rasa ingin defekasi. Orangtua harus mengajarkan bagaimana cara melatih anak untuk mengontrol rasa ingin berkemih, diantaranya dengan menggunakan pot kecil yang bisa diduduki anak, atau langsung ke toilet pada jam tertentu secara regular untuk berkemih. Anak didudukkan pada toilet atau pot yang bisa diduduki dengan cara menapakkan kaki dengan kuat pada lantai sehinngga dapat membantunya untuk mengejan. Latihan merangsang rasa untuk mengejan ini dapat dilakukan selama 5 sampai 10 menit, dan selama latihan, orangtua harus mengawasi anak (Supartini, 2004).

Namun demikian, setiap anak mempunyai kemampuan dan waktu yang berbeda dalam pencapaian kemampuan tersebut. Pencapaian kemampuan anak untuk BAB biasanya lebih awal sebelum kemampuan BAK karena keteraturan yang lebih besar, sensasi yang lebih kuat untuk $\mathrm{BAB}$ daripada BAK, dan sensasi BAB lebih mudah dirasakan anak (Hockenbery, Wilson, \& Wong, 2012). Kemampuan untuk mengontrol buang air kecil biasanya baru akan tercapai sampai usia anak 4 - 5 tahun.

Keberhasilan ataupun kegagalan toilet training dapat terjadi karena faktor kesiapan fisik, kesiapan mental, kesiapan psikologis dan kesiapan orang tua. Toilet training yang tidak tepat dapat menimbulkan beberapa masalah yang dialami anak seperti sembelit, menolak toileting, disfungsi berkemih, infeksi saluran kemih, dan enuresis (Hooman, Safaii, Valavi, \& Amini-Alavijeh, 2013). Berdasarkan fenomena di atas, bahwa kesiapan fisik, kesiapan mental, kesiapan psikologis dan kesiapan orang tua dalam toilet training memerlukan perhatian yang khusus.

Puskesmas Sibela Surakarta merupakan Puskesmas sayang anak, hasil laporan kunjungan bulanan dari Puskesmas Sibela Surakarta jumlah anak yang berobat enam bulan terakhir periode bulan Januari sampai Juni 2015 pada rentang usia 1- 4 tahun sebanyak 212 orang, yang terdiri 100 anak lakilaki dan 112 anak perempuan. Studi pendahuluan yang dilakukan oleh penulis dengan melakukan wawancara pada sepuluh ibu yang mempunyai anak usia toddler yang melakukan kunjungan di Puskesmas pada bulan Juli 2015 diperoleh informasi bahwa dua ibu mengatakan anaknya jarang memakai diaper (menggunakan jika bepergian agak jauh) dan melatih anaknya untuk BAK dan BAB ke kamar mandi, tiga ibu mengatakan anaknya sudah tidak mengompol pada malam hari dan sudah bisa melakukan BAK 
sendiri pada siang hari sedangkan untuk BAB masih harus ditemani karena anaknya belum bisa untuk cebok sendiri dan kadang-kadang BAB di celana. Dua ibu mengatakan anaknya apabila ingin BAK atau BAB memberitahu dan sudah mampu melakukan sendiri BAK dan BAB di kamar mandi karena sejak usia 1 tahun ibu mengajarkan untuk BAK atau BAB di kamar mandi. Dua ibu mengatakan anaknya setiap hari selalu memakaikan diaper pada anak, karena apabila tidak menggunakan diaper anaknya akan ngompol dan belum bisa menyampaikan keinginan untuk BAK atau BAB. Satu ibu mengatakan anaknya jika akan $\mathrm{BAB}$ atau BAK menangis dan mengompol pada malam hari. Hasil wawancara penulis dengan petugas Puskesmas didapatkan belum dijadualkan secara rutin, pendidikan toilet training pada anak toddler bagi para ibu, pemberian informasi hanya secara sekilas.

Belum semua orang tua yang mempunyai anak toddler mengetahui dan mempersiapkan dengan baik proses toilet training. Usaha untuk melatih anak BAK dan BAB dapat dilakukan dengan cara memberikan contoh dan anak menirukan secara benar, mengobservasi saat memberikan contoh toilet training, memberikan pujian saat anak berhasil dan tidak memarahi saat anak gagal dalam melakukan toilet training (Gupte, 2004). Salah satu strategi yang dapat digunakan orangtua untuk membantu mempersiapkan anak toilet training dengan menggunakan modul bergambar. Modul bergambar dapat menjadi bahan referensi bawah sadar, yang apabila bertemu dengan situasi yang serupa kelak akan memberikan respon seperti dia telah melihat bagaimana modelnya memberi respon (Alwisol, 2004). Belajar menggunakan modul bergambar memberikan keleluasaan para ibu untuk mempelajari dan mempraktikkannya dengan baik pada anak toddler tentang cara toilet training, sehingga diharapkan membantu keberhasilan anak toddler dalam toilet training.

\section{METODE PENELITIAN}

Penelitian ini bertujuan untuk mengetahui pengaruh modul bergambar terhadap peningkatan keberhasilan toilet training anak toddler di wilayah kerja Puskesmas Sibela Surakarta. Penelitian ini menggunakan metode penelitian eksperimen semu, dengan pendekatan one group pre and postest.

Penelitian dilakukan pada bulan April - Juli 2016 di wilayah kerja Puskesmas Sibela Surakarta.

Sampel yang digunakan pada penelitian ini adalah anak toddler usia 18 bulan sampai 36 bulan sebanyak 71 responden. Teknik sampling yang digunakan dalam penelitian ini adalah sample random sampling.

Kriteria inklusi pada penelitian ini adalah orangtua yang mempunyai anak usia 18 bulan sampai 36 bulan, bersedia menjadi responden penelitian dengan mengisi lembar persetujuan (informed consent). Kriteria eksklusi pada penelitian ini adalah anak dengan gangguan mental.

Untuk mengetahui pengaruh modul bergambar terhadap peningkatan keberhasilan toilet training anak toddler dengan uji t dependen (paired t test).

\section{HASIL PENELITIAN}

Rata-rata keberhasilan $r$ toilet
training sebelum diberikan modul
bergambar adalah 12.10 dengan
standar
deviasi 3.642. Rata-rata keberhasilan toilet
training sesudah diberikan modul


bergambar adalah 13.17 dengan standar deviasi 3.372. Rata-rata perbedaan keberhasilan toilet training sebelum dan sesudah diberikan modul adalah 1.070 dengan standar deviasi 2.805. Hasil uji statistik didapatkan nilai $\mathrm{p}=0.002$, maka dapat disimpulkan bahwa modul bergambar dapat meningkatkan keberhasilan toilet training pada anak toddler, dengan tingkat korelasi rendah yaitu nilai korelasi 0.683 .

Tabel 1

Keberhasilan Toilet Training Sebelum Dan Sesudah Diberikan Modul Bergambar $(\mathbf{N}=71)$

\begin{tabular}{ccccc}
\hline $\begin{array}{c}\text { Keberhasilan } \\
\text { toilet } \\
\text { training }\end{array}$ & Mean & SD & SE & $\begin{array}{c}\mathrm{P} \\
\text { Value }\end{array}$ \\
\hline Sebelum & 2.10 & .642 & 432 & .002 \\
Sesudah & 3.17 & .372 & 400 & \\
\hline
\end{tabular}

\section{PEMBAHASAN}

Ada beberapa cara mengajarkan toiltet training pada anak, yaitu dengan teknik lisan, teknik modelling, menggunakan modul bergambar, dan lainlain. Teknik lisan adalah usaha melatih dengan cara memberikan intruksi pada anak dengan kata-kata sebelum atau sesudah buang air kecil dan buang air besar. Teknik modelling merupakan usaha untuk melatih anak dalam melakukan buang air besar atau bauang air kecil dengan cara meniru atau memberi contoh untuk buang air besar atau buang aiar kecil secara benar. Strategi lain yang dapat digunakan orangtua untuk membantu mempersiapkan anak toilet training dengan menggunakan modul bergambar (Alwisol, 2004).

Pada penelitian ini didapatkan hasil bahwa modul bergambar dapat meningkatkan keberhasilan toilet training pada anak toddler, dengan tingkat korelasi rendah yaitu nilai korelasi 0.683 . Rata-rata perbedaan keberhasilan toilet training sebelum dan sesudah diberikan modul adalah -1.070 dengan standar deviasi 2.805 .

Belajar menggunakan modul bergambar memberikan keleluasaan para ibu untuk mempelajari dan mempraktikkan dengan baik tentang cara toilet training, sehingga membantu keberhasilan anak toddler dalam toilet trainng. Mengajarkan toilet training membutuhkan waktu, pengertian dan kesabaran. Hal terpenting yang perlu diingat adalah bahwa orangtua tidak dapat memaksakan anak untuk menggunakan toilet. Orangtua dapat mengajarkan toilet training pada usia $1-3$ tahun secara bertahap dengan menggunakan modul bergambar.

Suksesnya toilet training tergantung pada kesiapan yang ada pada diri anak dan keluarga terutama ibu. Keberhasilan toilet training memberikan keuntungan bagi anak, seperti anak dapat mengontrol buang air kecil dan buang air besar secara mandiri. Anak bisa melakukan sendiri buang air kecil atau buang air besar dan juga mulai mengetahui beberapa bagian tubuh dan fungsinya.

\section{KESIMPULAN DAN SARAN}

Modul bergambar dapat meningkatkan keberhasilan toilet training pada anak toddler dengan nilai $\mathrm{p}=0.002$. Terjadi peningkatan keberhasilan toilet training 1.070 point, dengan tingkat korelasi rendah yaitu nilai korelasi 0.683 .

Rata-rata modul bergambar dapat meningkatkan keberhasilan toilet training pada anak toddler di wilayah kerja 
Puskesmas Sibela Surakarta meskipun dengan tingkat korelasi yang rendah. Hal ini dibuktikan dengan adanya peningkatan point keberhasilan toilet training. Ibu-ibu toddler dengan dukungan kader supaya mempertahankan dan lebih ditingkatkan lagi motivasinya dalam mengajarkan toilet training pada anaknya, agar keberhasilannya dapat optimal.

Perawat hendaknya memberi dukungan pada ibu-ibu toddler, dan selalu memantau peningkatan keberhasilan toilet training pada toddler secara berkala di wilayah kerja Puskesmas Sibela Surakarta.

\section{DAFTAR RUJUKAN}

Alwisol. (2004). Psikologi Kepribadian. Malang Universitas Muhammadyah Malang.

Behrman, R.E., Kliegman, R.M \& Jenson, H.B. (2004). Nelson Textbook of Pediatrics. 17th Edition. Philadelphia. WB Saunders Co.

Hastono, SP. (2007). Analisis Data kesehatan. Jakarta : Fakultas Kesehatan Masyarakat UI

Hockenberry \& Wilson. (2012). Essentials of Pediatric Nursing. (Eighth Edition). St.Louis, Missouri : Mosby Elsevier.

Keen, D, Braningan, K L, Crusskelly, M (2007) Toilet Training For Children with autism : The effects of video modelling, hlm 291-303, http://www98

gnffith.edu.au/dspace/bitstream/ha ndle/10072/16968/47013_1.pdf?s equence $=1$., diunduh pada tanggal 12 April 2016

Mubarak dan Chayatin., (2009)., Ilmu Kesehatan masyarakat : Teori dan Aplikasi., Jakarta : Salemba Medika
Muscari. (2005). Panduan Belajar : Keperawatan Pediatrik. Jakarta : EGC.

Notoatmodjo., (1997), Ilmu Kesehatan Masyarakat., Jakarta : PT. Rineka Cipta.

Perrin, R. (2009). Pocket Guide to APA Style. (Third Edition). USA : Wadsworth, Cengange Learning.

Ridwan

$$
\text { Sunarto }
$$

H., (2010)., Pengantar Statistika.,

Cetakan Ketiga., Jakarta : Alfabeta.

Riyadi, S; Sukarmin. (2009). Asuhan Keperawatan Pada Anak. Yogyakarta : Graha Ilmu.

Salsabila., (2011)., Hubungan Pola Asuh Orang Tua Dengan Tingkat Keberhasilan Toilet Training Pada Anak Usia Pra Sekolah Di TK., Http://Skripsi-Qt.Blogspot. Com/2011/04/Hubungan-PolaAsuh-Orang-Tua-Dengan.Html., Diunduh Tanggal 14 Agustus 2015.

Sugiyono. (2008). Metode Penelitian Pendidikan Pendekatan Kuantitatif, Kualitatif dan $R \& D$. Bandung. Alfabeta.

Windiani \& Soetjiningsih., (2008)., Prevalensi dan Faktor Risiko Enuresis pada Anak Taman Kanak-Kanak di Kotamadya Denpasar., Sari Pediatri, Vol. 10 : 3., Oktober 2008 